\title{
Sobre familia y vasallaje en la España ilustrada: el fratricidio de Filomena.
}

Ana Isabel Fernández Valbuena

Universidad Complutense de Madrid. España

Las notas que se ofrecen en este trabajo quieren ser sólo unos apuntes para la reflexión sobre los valores familiares que defendían determinados sectores de la España ilustrada, partiendo de un drama del ensayista del siglo XVIII Tomás Sebastián y Latre: Progne y Filomena.

Sebastián y Latre $^{1}$ formó parte de un sector, al tiempo conservador y reformista, dentro de la polémica estética y moral que se dio en la España dieciochesca. Fue autor del tratado Ensayo sobre el teatro español ${ }^{2}$ (Madrid, 1773) con el que quiso dejar bien clara la preeminencia de la moral y de la intención didáctica en ámbito artístico y, especialmente, dramático; ética acorde con los valores ponderados por una élite ilustrada. Así lo expresa desde la misma dedicatoria de su ensayo, al Conde de Aranda:

No es ageno del Gobierno, que el Rey, nuestro Señor ha fiado à la sábia conducta de V. Exc.

el bolber los ojos por algunos momentos a un objeto tan importante como el Teatro: él debe ser escuela pública. ¿Qué importaria al Genero Humano ver las pasiones, virtudes, delitos, premios, y castigos de los Heroes de la antigüedad, si no consiguiesen instruirlos? ¿Ni que aprovecharia la viva pintura de las costumbres, si ridiculizando la deformidad de ellas, no nos hiciese aborrecible el vicio, y amable la virtud? ${ }^{3}$

En su ensayo, durante un largo prólogo, el autor habla de un amanecer sobre los Teatros, basado en la luz de la razón y del buen gusto, es decir, el que preconiza él mismo y que estima el más adecuado para el bien del país: "Un Teatro Christiano y conforme a la gravedad de la Nación Española”. Según él, estos principios se oponen a un público "protector del mal gusto" que juzga la decencia carente de fuego poético y la moralidad objeto de la melancolía.

Teniendo presente esta función, Sebastián y Latre realiza dentro de su propio ensayo una revisión dramática del mito terrible y ejemplar de la solidaridad entre dos mujeres hermanas, Progne y Filomena. Dicho mito ha gozado de amplia fortuna a lo largo de la historia, pero la versión de Sebastián y Latre merece, tal vez, un lugar de honor en la lista negra de la lucha por los derechos de la mujer. La defensa a ultranza de un concepto de familia y de monarquía, en el que deben primar los valores de obediencia y lealtad por encima de la propia dignidad de las personas, lleva a este autor ilustrado a condenar a las dos hijas del rey Pandíon, inmortalizadas en Las Metamorfosis de Ovidio ${ }^{4}$ al enfrentamiento y la muerte; todo por otro hombre-rey que ha obrado sin tener en cuenta la sólida relación de respeto y cariño que las unía. Así se justifica el autor en su Prólogo:

/.../ esta [historia] hubiera sido más verdadera, siguiendo à Ovidio; pero me he conformado con la regla de los mejores Maestros, que previenen no se saquen al Público sucesos atroces; porque son como ciertos delitos enormes, cuyos procesos se mandan quemar con los reos; y 
he tenido por conveniente, y aun preciso, el apartar de los ojos de los espectadores un horror, que tal vez por todas sus circunstancias no podria sostener nuestro Teatro.

De tal modo, el castigo no recaerá sobre el atribulado marido infiel -cuñado violador-, como en otras versiones españolas del Siglo de Oro; ni sobre el inocente hijo, como en el mito original, sino sobre la pobre Filomena, por haber puesto en peligro el estamento familiar: primero con su belleza, luego con su delación y, por último, con su incitación a la inmolación del sobrino como castigo del abuso de que ha sido objeto. Sin duda, esta interpretación dramática de Sebastián y Latre lleva a interesantes reflexiones de tipo social, moral y ético, que exceden lo filológico; no obstante, hay que partir de este punto, para enmarcar las razones que llevan a este estupendo artesano del drama a modificar un argumento, precisamente para argumentar la función didascálica del mismo.

El arte, tal como explica R. Andioc (1975: 429), ocupa en los ensayistas ilustrados españoles un lugar mucho menos importante que la moral, y que la moral social:

/.../ la polémica estética no es más que un aspecto de un conflicto ideológico más amplio.

Lo que se censura en ese teatro [el del siglo XVIII, que seguía los modelos dramáticos del

Siglo de Oro], es el que refleje, y, por tanto acredite, una ética a primera vista diametralmente opuesta a los valores ponderados por la élite ilustrada más o menos adicta al gobierno.

De ahí que, en términos generales, los ensayistas de la Ilustración sigan los principios de utilidad pública y educación de las costumbres. Si en el último cuarto del siglo XVIII se dieron en España actitudes de gran modernidad respecto al arte dramático y a las diversiones en general, como fue la de Melchor Gaspar de Jovellanos en su Memoria sobre los espectáculos públicos (escrita en 1790) ${ }^{5}$, la actitud de los sectores más inmovilistas fue la de mezclar "lo util y deleytoso", pero siempre con una intención moralizadora. A este sector pertenecía Sebastián y Latre, que acusaba a los autores dramáticos españoles de haberse olvidado "de hacer el Teatro tan util, como pudieran, cuidando solo de que fuese deleytable".

Centrándonos en el citado Ensayo sobre el teatro españolvemos que comprende, como ejemplo del tipo de dramas que deberían escribirse, una comedia y una tragedia. La primera intenta remedar El parecido en la corte, de Agustín de Moreto, y la segunda es precisamente la que ocupa este trabajo; dicho drama consiste en una refundición de la tragedia homónima de un autor español discípulo de Lope, Rojas Zorrilla $^{6}$ (1607-1648).

En la Filomena de Rojas, Tereo, esposo de Progne, y rey de Tracia, moría a manos de las dos hermanas, tal como explica Sebastián y Latre en su Prólogo:

/.../ sin tener en cuenta Progne aquellos debidos sentimientos de ternura, y veneración por su Esposo, y su Soberano, procurando inspirarles siempre las estrechas obligaciones de amor y fidelidad, con que nace todo vasallo para con sus Reyes.

Tal como recuerda R. Antioc. (1975: 457), esta fidelidad ejemplar al esposo y rey es la que también se predica a las casadas en la esfera inferior del drama, dentro del marco de ese estado en miniatura que constituye la célula familiar. Efectivamente, a juicio del autor del siglo XVIII, el teatro debía contribuir a

/.../ inspirar las maximas, que constituyen buenos Christianos, fieles Vasallos del Rey, hombres utiles al Estado y celosos ciudadanos por el bien de la patria.

Siguiendo este principio, Sebastián y Latre resuelve escribir una tragedia destinada a borrar de la memoria de los hombres "tan abominables exemplos", refiriéndose al desenlace ovidiano o al mismo de Rojas. Toma la fuente de Ovidio y parte de la versión de Rojas en algunos aspectos, como el hecho de devolver el habla a Filomena, mediante un Deus ex machina con el siguiente propósito:

Progne /.../ porque pueda / clamar a todo el Mundo contra un Monstruo /

que escandalo seria entre las fieras. (p. 11) 
Pero el autor se toma algunas licencias y resuelve la catastrophe de forma distinta, como ya se ha explicado.

A la luz del final que da a su propio drama, el "abominable ejemplo" del que pretende huir el autor, se tiñe de cierta ironía, pues, igualmente atroz a nuestros ojos de lectores-espectadores de comienzos del XXI es el ejemplo que él elige: el asesinato de Filomena a manos de su propia hermana, Progne, convertida por el autor en "modelo de Reynas y de Madres" - pero no ciertamente de hermana.

Lo cierto es que la justificación a semejante crimen se asienta, sobre todo, en una defensa a ultranza de la monarquía como institución necesaria para el mantenimiento del orden social, a cualquier precio. Así queda patente en la carta que acompaña al Prólogo del ensayo de Sebastián y Latre, y que firma el Muy Reverendo Padre Maestro Fray Onofre Andrés de Aso, teólogo y catedrático de Sagrada Escritura de la Universidad de Zaragoza. En ella no hace sino alabar la opción del tratadista y abundar en sus mismos conceptos:

La experiencia de todos los siglos nos demuestra que la desigualdad de los talentos /.../ causó en el corazón de los Principes, y en la Sociedad, guerras, injusticias y violencias; siendo forzoso, ò que esta Sociedad se destruyese à si misma, ò que la autoridad del Soberano fuese respetada como fundamento de su conservación /.../ El zelo por la Persona sagrada de los Reyes /.../ debiera llevarse desde hoi, /.../ sobre todos los escritos.

Para justificar sus opciones éticas y estéticas, el autor documenta las fuentes de su tratado: Aristóteles y Horacio, tratadistas extranjeros como el francés Saint Evremond, y nacionales como la Disertación sobre la Comedia Española que precede a las Comedias de Cervantes, de Don Blas de Nasarre (1749), o el clásico del siglo XVIII, el Arte poética de Luzán. De cada uno toma las teorías estéticas que le sirven para la demostración de su tesis, pero se desvía en la concepción argumental:

Si los Heroes del teatro Tragico de Francia, Corneille, Racine, /.../ llenaron el templo de Apolo de palmas, y laureles, hollaron impunemente el de la Religión y fidelidad de los cetros y Coronas. (Carta de Onofre A. de Aso)

No obstante, éstos son principios que presentan objeciones tanto al lector de hoy como al contemporáneo del autor, y se ofrecen como reflexión en boca de los distintos personajes. Según Filomena, por ejemplo, los reyes son humanos y falibles, y merecen ser castigados, pero su hermana Progne cuestiona el derecho a tomarse la justicia por propia mano.

Filomena /.../ Tereo atropelló: sus crueldades / lo hicieron transgresor de quantas leyes / la humanidad prescribe.

Progne Todo es cierto: / ¿Mas de que un Rey las rompa, y atropelle,/ se autorizará alguno, ni aun su Esposa, / para el egemplo? No lo dan los Reyes /.../

También, la voz de Menandro, consejero de Tereo, y alter ego del autor en sus reflexiones, se expresa en términos de familia y monarquía en su intento por reconciliar a la pareja real, cuya relación sabe herida de muerte.

Menandro ¡Itis viva; / vivan Tereo y Progne; triunfen, reynen: / reyne, Señora, amor, triunfe el cariño / viva la paz y todo se serene, / para bien del Estado y de la Patria; / para que Itis sin sustos los herede / tranquilo los disfrute; y vuestra sangre / difundida por Itis de Heroe en Heroe, / el Atico y la Tracia, el Universo / por él conquisten, domen y sugeten.

El propio Tereo, ya en el último acto, cuando el asesinato de Filomena se ha explicado como la única forma de detener la venganza que planeaba en su propio sobrino, se asombra de que la infeliz se hubiera atrevido a atentar contra la vida de un príncipe:

Tereo /.../ Monstruo horrible, /¿como no fue cuchillo penetrante / para tu

corazón, la queja, el llanto / de un inocente? Dime ¿como osaste /

contra un Príncipe, un Hijo de Tereo, / un sucesor...? 
Olvida Tereo que también Filomena, ultrajada por él, era princesa. Es, por tanto, sorprendente la calificación de su cuñada muerta y los reproches que Tereo debiera hacerse a sí mismo, cuya libido ha sido causa primera de toda la tragedia.

De modo que la Monarquía absoluta del siglo XVIII, y su origen divino, justifican el sometimiento de cualquier otra valoración moral a este principio de soberanía, heredada directamente de Dios. Así lo explica en su carta Onofre, A. de Aso:

En otra escena propone V. M. con particular delicadeza las más christianas maximas, y aquellos religiosos sentimientos, que debe tener el hombre fiel, nacido para mantener la unión en la sociedad, y el esplendor de la Soberanía. (Carta de De Aso, Onofre)

De tal suerte, la decisión final de Progne, que durante toda la tragedia se debate en la duda, está dictada, según de Aso, por su amor de madre, pero, sobre todo por su sentido del deber como vasalla y esposa, antes que como hermana o princesa, hija del rey de Atenas:

Progne es mas que hija de Pandion, y hermana de Filomena: esposa digo de Tereo y madre de Itis. Estos sagrados respetos, tan propios como debidos à la Magestad y à la naturaleza, la inspiran una pronta y generosa resolución. (Ibidem)

Parece, entonces, que los vínculos familiares que han de respetarse, a juicio de estos caballeros ilustrados, son fundamentalmente los de descendencia, no los de ascendencia, y que, en cualquier caso, su sumisión a la soberanía real es la razón de ser de la familia. Soberanía = orden = nación unida, y el verdadero amor conyugal es el que se pone al servicio de estos principios. Hasta tal punto, que Tereo, quien al comienzo de la tragedia confesaba haber perdido todo interés por su esposa y estar a merced de una pasión sin rienda, sólo cuando su esposa se ha convertido en fratricida para defender la unidad de su familia de descendencia, parece sentir de nuevo cierta atracción por ella:

Tereo Progne, Señora, / mi gratitud... mi amor, no sé explicarme; / han visto en vos, para mayor asombro, / el modelo de Reynas, y de Madres.

Todas estas ideas impregnan una tragedia sabiamente construida, donde la dosificación del suspense funciona hasta el momento final, pues ni siquiera cuando Progne sienta a la mesa del banquete a su marido, el rey, sabemos si lo que le ofrece de cena son los miembros descuartizados de su hijito, como en el mito ovidiano, o no. La función de la catástasis, de retrasar la resolución de la catastrophe, nos presenta a una Progne turbada por su crimen, cuya víctima el espectador todavía ignora:

Progne Dioses, lo que mi esposo mas quería / os he sacrificado /.../

Así se expresa, a su salida a escena, sola y ataviada para el convite. Pero, ¿qué es lo que más quería el esposo? ¿Su hijo amado? ¿La cuñada que lo ha cegado de deseo?

Progne ¿No he cumplido / lo que juró mi fé? ¿No he dado esmalte / al Trono, à mi lealtad, y à mi grandeza / con una acción, que acaso en los Anales / no se ha de contar otra? /.../ ¡duro combate! / conseguí una victoria, cuyo triunfo, / melancólico luto hará que arrastre.

Durante toda la tragedia, el autor nos ha presentado a una Progne herida en su dignidad de esposa y de hermana, y deseosa de venganza, y al tiempo presa de las dudas sobre el camino a seguir. Actitud que le sirve para dialogar sobre los asuntos que como ilustrado quiere tratar: la soberanía real, la necesidad de encontrar un equilibrio entre las pasiones humanas y los deberes de la monarquía, la obediencia, el respeto a las costumbres cristianas. Sentimientos y actitudes más que loables en un estado de Monarquía absolutista, pero que no casan con una situación de partida en la que la lujuria y la crueldad se han cebado en una víctima inocente, pisoteando el respeto a los valores familiares tradicionales de la paternidad y la hermandad.

Pero el autor sabe manipular sus elementos dramáticos para hacerlos creíbles y, 
así, nos presenta una Filomena, no sólo "parlante", sino poseedora de una elocuencia poderosa, al servicio de su único objetivo: la venganza más cruenta. Sus rasgos son más crueles porque contrastan, en su determinación, con los titubeos cristiano-familiares de su hermana, y con la debilidad libidinosa del cuñado, que no ha querido matarla para seguir gozándola, pero le ha cortado la lengua para no tener que escuchar los merecidos reproches a su infamia.

Tereo es dibujado como un hombre preso del deseo y temeroso de las consecuencias de un impulso que estima mayor que él mismo: son "los astros" que lo empujan. A lo que su consejero, Menandro, objeta:

Menandro La influencia, / y poder de los Astros nos inclinan; / pero a nuestro alvedrio jamás

fuerzan. /.../ Amad, Señor, amad a vuestra Esposa; / arrancad las raíces, que envenenan / ese Real corazon.

Menandro es la voz "cristiana" y sensata; aunque se refiera a dioses paganos, habla de una "Deidad inaccesible", cuyos designios no deben quebrantarse, y defiende los valores familiares. Seguramente es él, con sus consejos, quien modifica el curso de la revancha de Progne, suavizando el sentido trágico de la venganza de los dioses:

Menandro Si Júpiter Tonante, / el rayo de su diestra fulminára / contra quantos lo enojan, yá en volcanes / hubiera ardido el Mundo: es mas piadoso.

Efectivamente, vemos una evolución en el personaje de Progne, determinada por las conversaciones que va teniendo con su hermana Filomena, con Menandro y por sus propias y contradictorias reacciones ante los acontecimientos. En el I Acto sus palabras son sólo un mecanismo diegético, en su narración a su dama, Eumene, de lo ocurrido a su hermana, pues el drama comienza ya in media res, con la fuga de Filomena de su prisión. Por su forma de contarlo, deducimos que su dolor y su rabia se encaminan hacia la venganza:

Progne /.../ quebrantando / los vinculos de amor, la fé y promesas / à una Esposa à una

Hermana, à un tierno Padre, / que gustoso le daba en su hija bella / las ultimas delicias de sus ojos. /.../ [el rey] Conmigo disimula, y manifiesta / un cariño afectado, que discierno:

/ pero encubro mis iras y mis penas, / hasta que la ocasión se proporcione / de ayudar a mi Hermana y sostenerla, / para vengarnos ambas.

Pero a lo largo del II Acto, las llamadas a la acción de Filomena la espantan y la empujan al tiempo. Filomena le arranca en un momento de furia un juramento:

Progne /.../ llegaré a que mis manos se ensangrienten / en lo que este inhumano mas estime. Filomena Pues jura por los dioses lo que ofreces.

Progne Por Minerva, y por Marte, Tutelares / de Atenas y de Tracia, te promete / esta infeliz hacer quanto propongas.

Filomena propone entonces dar muerte a Itis y ofrecerlo al desalmado como manjar, pero Progne retrocede en su intención horrorizada y se ofrece a morir ella misma. Ahí comienza a atormentarle la duda entre los afectos de madre, los de hermana y el despecho de esposa traicionada; éste es, precisamente, uno de los aspectos que más la alejan del mito ovidiano, en el que la decisión y la determinación de las dos hermanas no ofrecen ningún resquicio a la duda; se convierten en ejecutoras de una especie de ley universal del Talión, donde los lazos de hermandad y el sentido del honor de pertenencia a una aristocracia en sentido moral (la ateniense, como hijas del rey Pandíon) están muy por encima de los valores que se ponderan en esta versión dieciochesca. Tereo, con su infamia, se ha desacreditado, como marido, como yerno e, incluso, como rey. Ni él, ni su descendencia merecen vivir; aunque todos mueran, el equilibrio natural y moral debe restablecerse, y no ha de permitirse la impunidad. En ello reside probablemente la belleza salvaje de este mito clásico que se ofrece como un extremo gesto de honra en su dimensión femenina. 
El drama de Sebastián y Latre, en cambio, al no plantear directamente al espectador la primera parte de la historia (recordemos que esta revisión comienza in media res) tamiza ya los actos de los personajes, y nos presenta a Tereo como un rey débil ante sus caprichos pero cruel en sus propósitos y a una Filomena cruenta instigadora del crimen. No se da evolución en este personaje, que ya ha llegado al clímax dramático cuando la tragedia comienza, y está, en su elocuencia, más cerca de los sentimientos que Ovidio cincela para su hermana:

Filomena /.../ ¡Oh, ingrata Hermana!. Pero Hermana no eres, / quando la atrocidad has olvidado / con que triunfó Tereo infamemente / de tu honor en el mio; y la vileza / de que obstinado y perfido rompiese / la confianza, que mi padre le hizo / entregandole en mi, justo es lo acuerde, / el ultimo consuelo de sus canas.

Su hermana, en cambio, se debate en un mar de sentimientos encontrados, cuyo proceso se convierte en el verdadero debate moral que el autor quiere poner sobre las tablas. El Acto I había concluido con un presagio de inmolación reivindicativa de su condición de princesas ultrajadas:

Progne Las hijas de Pandíon morirán antes / que segundo atentado le consientan.

Pero en el II, un largo monólogo -stream of conciousness- plantea sus dilemas sobre la venganza que exige Filomena en el hijo de Tereo, y la de la tensión de Progne entre su amor de madre y de hermana:

Progne /.../ ¿por ser Hermana (me ahoga el sentimiento) / dejaré de ser Madre? No consienten / mi amor, y mi ternura tal fiereza: / antes para librarte de la muerte [al hijo] / me armaré de constancia /.../ / /../ jasí el valor de Progne descaece, /.../ y a una debil ternura la via cede? / ¡Oh! animo femenil! ¡pecho cobarde! / ¡villano corazón! que así desmientes / la sangre que te aníma /.../

Muera, pues, muera este hijo, de aquel arbol / la unica rama se desgage, y quiebre; / acabe entre los hombres la memoria / de tan inicua y barbara progenie.

Monólogo en el que termina venciendo su amor de madre:

Progne Excelsos Dioses, / siempre benignos, aunque justos siempre, / conciliad los afectos de una Madre / con la severidad de vuestras leyes.

En este mismo II Acto, la sagacidad del autor, que quiere transformar la imagen de la víctima en verdugo, recurre al ardid de poner en boca de Filomena la acusación de la posible muerte del pequeño a manos del rey, junto a la de las dos hermanas:

Filomena Su venganza / tampoco ha de saciarse con tu muerte; pues por no conservar memorias tuyas, el sacrificio, que ahora no consientes, hará tu Esposo. /.../

Progne parece entonces decidirse a darle muerte con sus propias manos, pero en el acto siguiente (Acto III) aparece cada vez más atormentada por las dudas, mientras el furor de Filomena llega casi al paroxismo, convirtiéndola en una manipuladora:

Filomena Nada temo, ni miro: en este empeño / me hallará tu ternura inexorable: / un breve plazo tienes, determina, / odio, y ternura puestos en contraste, / ¿qual en ti pesa más; esta hacia el Hijo, / o aquel hacia Tereo?

Progne /.../ ¿Quién se vio en tal conflicto por su Hermana? / ¿Quien hasta aquí se halló en el duro trance / de tomar un partido, que a esos Orbes / paráse el curso, y las luces ocultase, / por no mirarlo Apolo?

"Tomar partido", eso es lo que el autor exige a este personaje-modelo, que resuelve su conflicto y nos lo narra al término del III Acto, para hacernos partícipes de su "acertado" razonamiento. Lo cuenta ante el cadáver ensangrentado de su hermana, cuya aparición ha truncado la armonía del convite que la pareja real celebraba:

Progne /.../ con las frases / que su furor y agravio la inspiraban, / persuadia à mis iras, que 
atentase / para satisfacción de sus injurias, / contra ... no lo pronuncie... el decir baste / que ofendida, fui leal, con zelos cuerda; / y Esposa y Reyna à un tiempo.

/.../ viendo que ningún esfuerzo vale, / que morir mi Hijo, ú ella, era forzoso: el matarla elegí, y anticiparme / à evitar con el mío, el duro golpe / que ya ví descargado, y en el ayre / lo detuvo la muerte, que en su pecho / la introdujo el invicto amor de Madre.

Progne es modélica en su lealtad de esposa, en su sensatez regia, en su "invicto amor" materno. La satisfacción de la venganza del mito de Ovidio se ha dado la vuelta y el drama se liquida sumariamente con un escueto comentario de Tereo y una acotación escalofriante, que borra a Filomena del panorama:

Tereo: Quitad ese espectáculo (llevanse à Filomena).

La explicación de Progne la redime del fratricidio y resume por su boca la solución que el autor propone a este drama de estado y de familia y, acto seguido, todos se encaminan al templo de Marte a dar gracias, vitoreando a Itis, el heredero de un sistema que debe perpetuarse.

En un intento de superar el aspecto histórico y social de esta versión mítica, conviene recordar que la revisión de los mitos clásicos supone siempre una dialéctica entre el peso de la tradición y su consideración en el plano de la estética de la recepción y de su eficacia. En ese marco se contempla el axioma que concibe al autor clásico como un reflejo de nuestra sensibilidad moderna, puesto que sus obras no las escribe sólo él: las escribe su público, el de su presente y el del porvenir.

Sebastián y Latre fue intérprete de su tiempo y nosotros juzgamos el suyo estableciendo en el ámbito literario un diálogo abierto con la posteridad. En este caso, sobre los derechos de las personas y sus implicaciones sociales, puesto que la relación de la literatura con la historia se concreta en su aportación a la construcción de la sociedad humana. Quizá lo más interesante sea preguntarse, a partir de las distintas versiones de Progne y Filomela, por las soluciones que cada sociedad debe dar a estos problemas.

La experiencia del lector como experiencia de la vida es un aspecto del que trata H. R. Jauss (1989: 71-72) en su libro sobre el sentido de la Historia de la literatura: A confronto del (ipotetico) non lettore, il lettore è privilegiato perché non ha bisogno di urtare contro un nuovo ostacolo per ottenere una nuova esperienza della realtà. L'esperienza della letteratura può liberarlo dagli adattamenti e dalle costrizioni della vita, in quanto lo obbliga ad una nuova percezione delle cose. L'orizzonte di attesa della letteratura si caratterizza rispetto a quello della realtà storica perché esso non solo racchiude esperienze compiute ma anticipa anche possibilità irrealizzate, amplia il margine limitato del comportamento sociale a nuovi desideri, esigenze e scopi e così apre la strada all'esperienza futura.

Se trata, en mi opinión, de una previsión en exceso optimista, la de pensar que la literatura pueda aliviarnos el doloroso camino del aprendizaje, pero, como mujer del siglo XXI que vive en un país monárquico, como hermana y como madre, no me queda sino esperar que Jauss tenga razón, y confiar en que en el mundo habrá lugar algún día para una solución razonable -que no racionalista- al dolor de Progne y Filomena. Mis hermanas. 
${ }^{1}$ Nacido en Zaragoza antes de la segunda mitad del siglo XVIII, y muerto en 1792, fue cronista de su ciudad, autor también de la comedia Las aventuras de Telémaco, hijo de Ulises (1768); así mismo fue responsable de la versificación de la versión española de Britanico de Racine, traducida en prosa castellana por Don Saturio Iguren (1764).

${ }^{2}$ Dicho ensayo no ha sido reeditado desde su última publicación de 1773, en la Imprenta de Pedro Marín, Madrid. El Conde de Aranda costeó esta segunda edición así como la representación de los dos dramas que lo ilustran, que también fueron representados en Zaragoza. Estos datos han sido recopilados en De Latassa y Ortín, F. (1801). Pueden consultarse ejemplares del ensayo de Sebastián y Latre en las Bibliotecas Nacional y Municipal de Madrid.

${ }^{3}$ La cita reproduce textualmente la dedicatoria del original de 1773 , por lo que ciertos rasgos ortográficos y acentuativos difieren de la norma del castellano de hoy.

${ }^{4}$ Recordemos brevemente el mito que desarrolla el Libro VI de Las Metamorfosis de Ovidio: Pandíon, rey de Atenas, da a su hija Progne en matrimonio a Tereo, rey de Tracia, que lleva a su esposa hasta su nuevo país. Nace un hijo de la pareja, Itis, y Progne, deseosa de ver a su hermana tras cinco años de matrimonio, ruega a su marido le permita viajar, o vaya a rogar a su padre que ésta la visite en Tracia. Tereo bota un barco y consigue que su suegro, a pesar de su avanzada edad, acceda al viaje de su hija. Pero la belleza de Filomena y la lujuria innata del cuñado, encienden su apetito hacia la joven y al desembarcar la arrastra hasta un oscuro caserío en un bosque y la viola. La joven, tras el cruel acto, comprende la terrible situación en que el ultraje la ha colocado y ruega la muerte, amenazando con divulgar su deshonra, lo que provoca la ira y el temor del cuñado, que, para evitar la delación, desenvaina su espada y le corta la lengua. Tras ello, la viola una y otra vez y la encierra en una torre, narrando a su esposa una falsa muerte. Transcurre un año y Filomena, incapacitada para hablar, cuelga una urdimbre de un telar y teje en él su historia, que una esclava entrega a la infeliz hermana. Al comprender lo sucedido, Progne piensa sólo en la venganza, libera a la prisionera durante las fiestas de las Bacantes y la lleva a palacio, donde asegura estar dispuesta a todo para vengarse, tal como merece el cruel violador, el infiel marido, el desvergonzado yerno. La llegada de su hijito le sugiere la posible venganza: acuchillan al pequeño, cocinan su miembros y los sirven como un festín a Tereo, que al comprender que ha engullido las entrañas de su amado hijo persigue a las dos hermanas con la espada en mano. Ellas son entonces transformadas en golondrina y ruiseñor y él en abubilla, un pájaro de agudo pico que persigue sin cesar a estos dos últimos.

${ }^{5}$ Publicada en 1802, se había escrito en 1790 para ser leída como discurso ante la Real Academia de la Historia, con vistas a la reforma de la correspondiente legislación. Se trata de una obra que defiende la necesidad de los espectáculos y diversiones, desde la óptica de un racionalismo absolutista bastante moderno y fuera de todo juicio moralizador. Es prácticamente una declaración de principios del ideal político-económico de un sector de la Ilustración española muy distinto del que defendía el aragonés Sebastián y Latre; Jovellanos deja a un lado las discusiones 
sobre la moralidad de los espectáculos públicos, que considera una polémica "añeja” y superada.

${ }^{6}$ Se trató de un autor dramático preocupado en su dramas por los temas de los celos y el honor, largamente tratados en el teatro español del Siglo de Oro.

\section{Bibliografía}

Aguilar Piñal, F.: (1984-5), Bibliografía de autores españoles del siglo XVIII, v. III y VIII, Madrid.

AnDIOC, R.: (1975), "El teatro en el siglo XVIII", en Diez Borque, J.M. Historia de la literatura española (ss. XVII y XVIII), Biblioteca universitaria Guadiana, Madrid.

De Latassa y Ortín, F.: (1801), Biblioteca nueva de los escritores aragoneses, Oficina de Joaquín de Domingo, Zaragoza, vol. V (1753-1795). Jauss, H. R.: (1987), Perché la storia della letteratura, Guida, Napoli. Jovellanos, G. M.: (1812), Memoria sobre los espectáculos públicos, leída en la Real Academia de la Historia, 1796, Madrid.

Sebastián y Latre, T.: (1773), Ensayo sobre el teatro español, Imprenta de Pedro Marín, Madrid. 